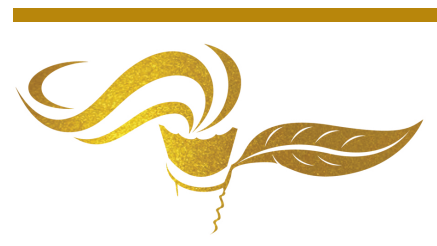

\title{
Complexity of Global Refugee Crisis: Needs for Global Transdisciplinary Collaboration
}

\author{
Moran, D., Gulbulak, U., Ertas, A., Yancey, S., Cody, C., Puente, K., Zinsmeyer, J., \\ Agbontaen, I., Alejandra, C., Bakir, A. H., Baucum, H., Daniel, M. E., Gabriel, R., \\ Heriberto, M., Kodwo, T., Lopez, E. G., Melendez, O., Nicholas, E., Rippert, J., \\ Yadav, S., Watts, R., Yunseon, K., Zatloka, M.
}

Texas Tech University, Department of Mechanical Engineering, Lubbock, Texas 79409,

Received March 27, 2020; Revised April 27, 2020 Accepted May 5, 2020

Available online May 7, 2020 at www.atlas-journal.org, doi: 10.22545/2020/00137

\begin{abstract}
Deople are on the move for many reasons such as war and civil war, human rights, violation, economic, social, climate, environmental, political, and individual reasons that create these changing aspects. In such complex situations, the need to flee (forcibly displaced) versus the choice to leave (migration) can be difficult to determine. The issue of refugee resettlement is complex and includes many factors to consider. Factors being considered for their impact on resettlement include budget and cost issues, federal law and policies, administration challenges, security screening process, education and training, health and housing, crime rate, socioeconomic issues and many others. The objective of this article is to discuss how the aforementioned factors relates and interact with one another using Interpretive Structural Modeling $(I S M)$.

ISM methodology implementation against this problem was consisted of a group of 25 undergraduate students in senior design class, all pursuing Mechanical Engineering degree at Texas Tech University, two Ph.D. students, one faculty member in design, four research engineers from different companies. This group recognized significant difficulties and challenges in carrying out successful refugee resettlement and sought to identify the main factors affecting the problem and how they were interrelated, with the goal of improving the rate of success for these displaced individuals.
\end{abstract}

Keywords: Refugee resettlement, interpretive structural modeling, forcibly displaced, migration.

\section{Introduction}

People are on the move for many reasons such as war and civil war, human rights, violation, economic, social, climate, environmental, political, and individual reasons that create these changing aspects. In such complex situations, the need to flee (forcibly displaced) versus the choice to leave (migration) can be difficult to determine. 
Moran, D., Gulbulak, U. Ertas E., Students from 2020 Capstone Design, ME-Section-5 Class

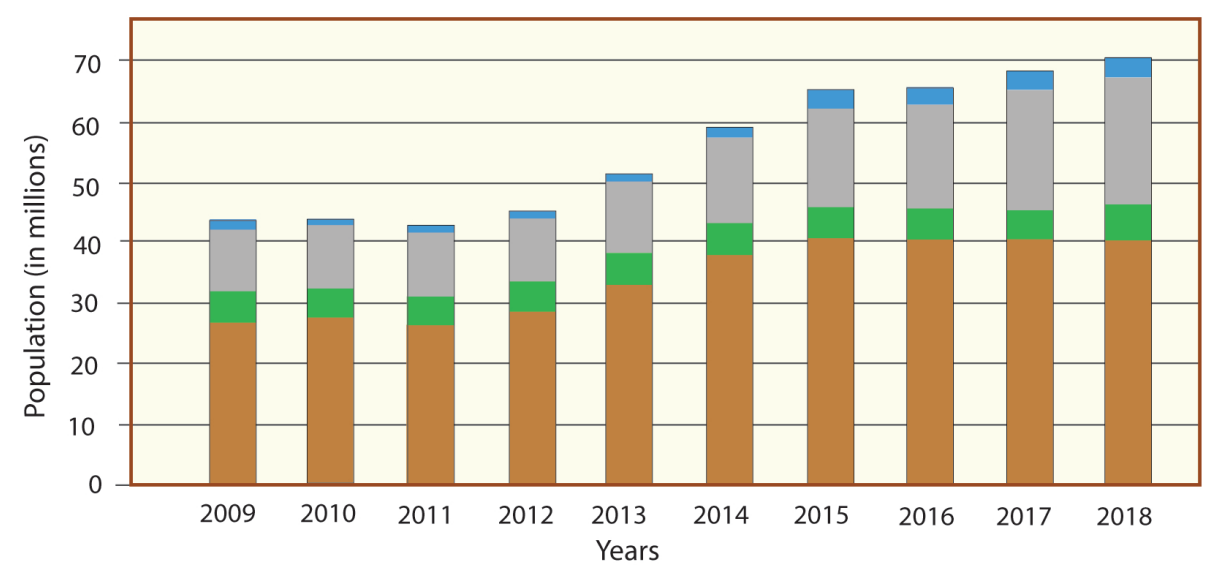

Internally displaced people $\square$ UNRWA refugees $\square$ UNHCR refugees $\square$ Asylum-seekers

Figure 1: Global forced displacement during 2009-2018 (recreated from [1]).

The worldwide population of forcibly displaced rose by 2.3 million people in 2018 reaching to 70.8 million - 20 people are displaced every minute in a day. The worldwide population of forcibly dislocated people grew considerably from 43.3 million in 2009 to 70.8 million in 2018, reaching a record high as shown in Figure 1 [1]. This increase took place between 2014 and 2015, cause to move mainly by the Syrian conflict along with other conflicts in the region such as in Iraq, Yemen, and Sudan as well as other poor countries. The complexity of the issue makes it difficult to understand global refugee problems.

\subsection{Challenges of Managing Refugee Resettlement}

Successful resettlement of refugees is the overall goal of any government that is offering asylum to any displaced people. To define resettlement as the integration of refugees into the host society with government assistance but transitions to self-sufficiency and the end of government aid being the completion marker. The administrative and programmatic factors that have been perceived as most important to successful refugee economic self-sufficiency. It is known that refugees have been successful in obtaining employment but key challenges for economic self-sufficiency remain. Some of these challenges are like those faced by low-income people in mainstream programs. The most common challenges that are included: resource issues, transportation, language barriers, and hard-to-serve clients [2].

The issue of refugee resettlement is complex and includes many other factors to consider. Factors being considered for their impact on resettlement include: budget and cost issues, federal law and policies, administration challenges, security screening process, education and training, health and housing, crime rate, socioeconomic issues and many others.

\section{Method}

The focus of this section is to discuss how the aforementioned factors relates and interact with one another using Interpretive Structural Modeling (ISM). Interpretive Structural Modeling (ISM), a well-established methodology for handling and decomposing complex problems was proposed by Warfield in 1973 [3]. ISM identifies and summarizes relationships among specific parameters and provides fundamental understanding of how those parameters relevant to the complex problem. Thus, helps researchers to structure complex problems in a meaningful way to overcome challenging unstructured problems [4]. 


\subsection{Context}

Transdisciplinary Collective Intelligence: ISM methodology implementation against this problem consisted of a group of 25 undergraduate students in senior design class, all pursuing Mechanical Engineering degree at Texas Tech University, two Ph.D. students, one faculty member in design, four research engineers from different companies. This group recognized significant difficulties and challenges in carrying out successful refugee resettlement and sought to identify the main factors affecting the problem and how they were interrelated, with the goal of improving the rate of success for these displaced individuals.

\subsection{Process}

Effectiveness in accepting and integrating immigrants into a new home country requires transdisciplinary collaboration among, and within, institutional sectors in the receiving countries. Partnering and joining must occur between organizations such as: social services; education; government; community-based organizations, and others.

The working group developed transdisciplinary collective intelligence using Interactive Collective Intelligent Management (ICIM) Workshop to investigate the issue. (1) The Nominal Group Technique (NGT) was used to develop and clarify a list of factors affecting the complex issue [5], (2) Interpretive Structural Modeling (ISM) process was used to develop:

(a) Structural self-interaction matrix

(b) Final reachability matrix

(c) Digraph

(d) MICMAC Analysis

The working group identified nine factors for how to handle complex issues of refugee settlement. The factors were grouped into six levels. Through MICMAC analysis, it was shown how these factors are interrelated to support the successful refugee settlement (see Figure 2 for Sequence of activities to develop an ISM model).

\subsection{Content}

The working group developed a set of factors affecting complex issue of refugee settlement showing how a select factors of the problem they identified were related to each other. One of the Ph.D. students, Utku Gulbulak, who is familiar with the ICIM facilitated the workshop.

\section{Identifying Factors}

During the first stage of the workshop, potential factors which affects the successful refugee settlement were identified. One of the methodologies that has been found useful was NGT structured method for group brainstorming that encourages contributions from group members and enables quick agreement on the relative importance of issues, problems, or solutions. NGT was used to obtain and specify potential factors. The working group developed twenty factors affecting issue in hand.

\subsection{Structuring the Factors}

Following the development of factors, a part of NGT process was used to determine which of the factors were most important. From the set of twenty factors, the following subset of nine were structured using methodology of ISM. Those were the ones receiving the highest scores in the voting on most important main factors. 


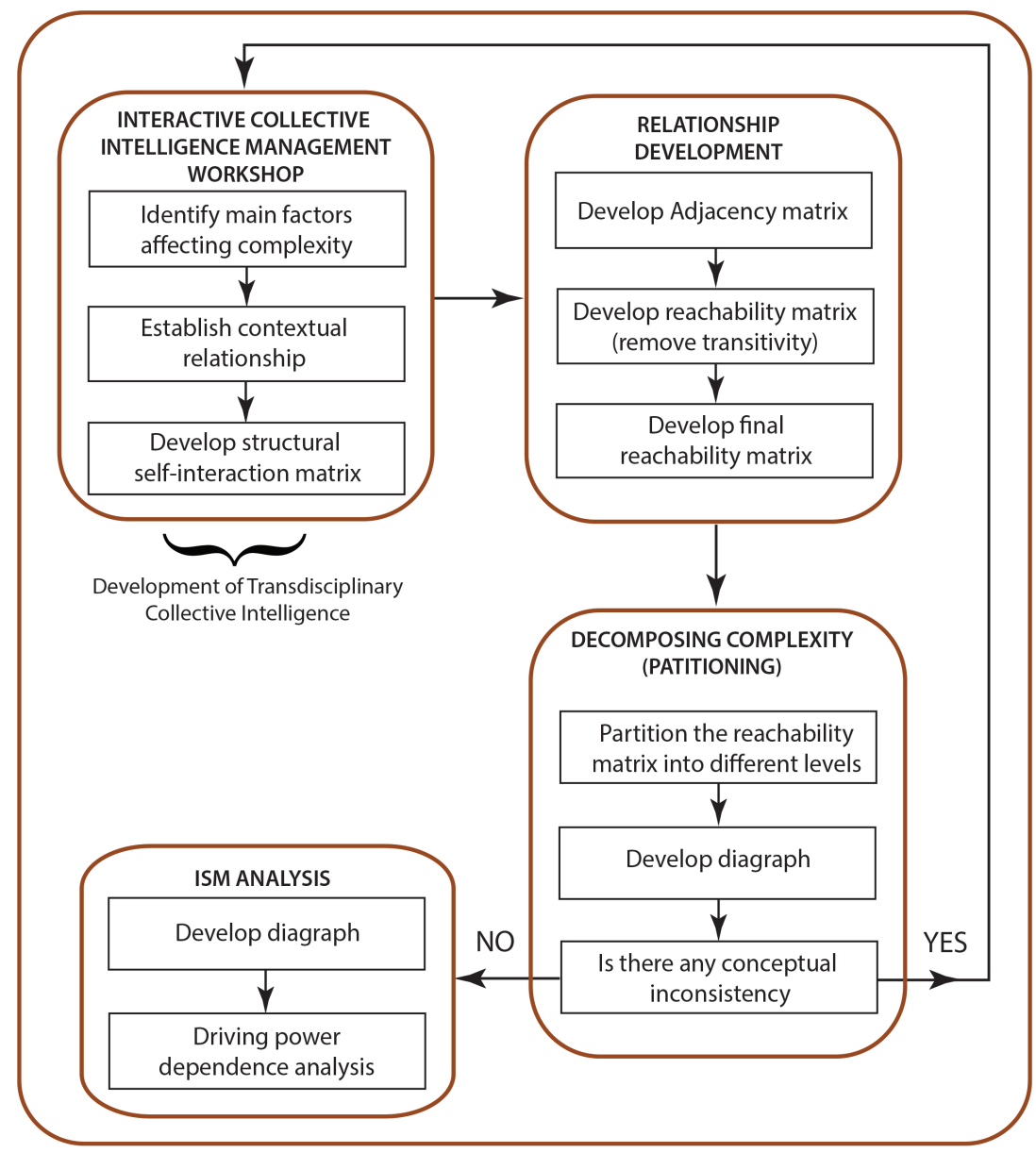

Figure 2: Sequence of activities to develop an ISM model.

\subsubsection{Budget (Cost)}

There are various costs that the Office of Refugee Resettlement (ORR) takes into account in the budget for funding refugee resettlement. The first and most obvious being the monetary costs: funding for transitional and medical services, social services, preventive health, shelter, utilities, supplies, training and education etc. Of course, the higher quality of the product or service provided to refugees translate to the higher cost. However, the minimum standards needed to make sure planned settlements support refugee communities to live with security and in a healthy environment which provide them quality of life. To determine the most feasible investment, depending on factors such as federal law and policies, the budget request is formulated based on the number of people in need.

\subsubsection{Policies and Rules}

Federal (Nation-State) laws and policies are significant when dealing with a wave of refugees trying to enter a new country. They dictate how effective a refugee crisis can be handled by a host country. Furthermore, the laws and policies set up how the country is going to respond to the situation. According to the Lumina Foundation, the federal policy "must support widespread change that puts the needs of individuals and society first" [6]. Whether it could be a temporary or permanent solution, the host country is responsible for accommodating the refugees and creating the laws that will govern them. The host country creates 
these laws and policies in order to offer protection, shelter, and life to the refugees - facilitating the process of resettlement. Nation- State policies and rules can also, on the contrary, limit the number of refugees entering the country and hinder the resettlement processes.

\subsubsection{Screening Process}

Refugees seeking resettlement must pass through a series of steps planed at ensuring they will not pose a security risk to the hosting country - security is among the top priorities of a nation.

In the last couple of years, nations have come a long way in finding ways to intercept threats and stopping them before they can happen. This is in part because of new technologies that can pick up encrypted communication and certain pattern of messages being transmitted around the globe paired with the work of the various intelligence communities for host countries.

In the United States, the 9/11 tragedy of 2001 [7] drove surveillance changes within the intelligence community which provide greater sets of data for evaluating incoming asylum seekers from "high risk" countries. Following 9/11, strengthened border and airport security provided additional measures for efficient and more effective measures for evaluating persons entering the country. This increased security posture within the U.S. since $9 / 11$ has seen positive results accompanied by the downsides of strained relationships between the U.S. and countries that have had to ban due to security reasons and the general view of the population these countries and the rest of the world [8].

U.S. is one of the most diverse and forward-thinking countries in the world however, U.S. still must stand firm when it comes to putting the interest of the country and people first. This conflict of selfinterest versus world relations goes on to affect processes like receiving refugees from war torn countries and disaster-stricken countries. Having to screen refugees for reception and placement together with making sure that U.S. is not putting the interest and safety of the people of the nation at risk continues to be a challenge for the nation and the world.

In the U.S., the Resettlement Support Center (RSC), contracted by the U.S. Department of State (DOS), handles an interview and collects the refugee's personal data and background information for the screening process. The United States determines the number for refugee admissions through the president and congress on a yearly basis. Applicants for the refugee program must pass a security screening to confirm that they do fall under the description of a refugee in addition to health and criminal history. Those who pass a security check and are within the number of admissions are then handed over to private voluntary agencies that handle refugees' basic needs as well as employment counseling. The United states policy also states that one year after admission, they can apply for permanent status. Followed by naturalization, which occurs after five years from admission [9].

Security screening process varies from country to country. It also takes into consideration where the refugees are coming from. When Canada took in 25,000 Syrian refugees security was one of the top priorities. They focused mainly on people who are considered low security risk but are vulnerable to danger. These people include women, complete families, and members of the LGBTI community. When they came into Canada, they went through a vigorous screening process. The process was made up of pre-identification of refugees, immigration and security interviews, identity and document verification, and re-checks of identification upon arrival [10]. In the European Union (EU) it is much harder to control. Countries are subjects to refugees seeking shelter from countries are able come directly to their borders. This makes it much harder to implement policies because they face chaotic situations every day. In the EU they use private agencies such as Frontex and EASO to support these screenings [11]. They mainly focus on running background checks to screen for criminal records and terrorist involvement. While the EU is trying to improve their screening processes, it has been difficult to do so. Since many countries are so behind in the security process it would take many years to get to the standard set by the U.S.

\subsubsection{Administration Challenges}

Administration challenges regarding the logistics and bureaucracy in the execution of decisions for resettling refugees will delay resettlement. "Turkey continues to host the largest number of refugees worldwide, 
with close to 4.1 million refugees, including 3.7 million Syrians and nearly 400,000 asylum-seekers and refugees of other nationalities [12]." The ability to provide for such a large influx of refugees while simultaneously documenting every individual and the services provided to them is essential for successful resettlement.

Obtaining information about the refugees and how they are faring is the only way to know if current administration policies are achieving their desired goals. One key metric for successful resettlement is measuring the time between the influx of refugees and successful resettlement. The greater this time of resettlement, the greater the cost to the host country which is accompanied by frustration of both parties and a prolonged the suffering of the refugees. "The main challenges remain the pressure on national resources and the availability of services for refugees and host communities. While state institutions are addressing these challenges, the protracted nature of the refugee situation has drawn public attention to the social impact of the refugees' presence [12]." Resettlement occurring in a timely manner increases the likelihood that it will be successful. "History shows a well-established pattern: as the number of refugees and the length of time they remain in a host country grows, the citizens of that country become less willing to provide for them [13]." Therefore, increasing administration efficiency will reduce the hindrance to resettlement.

Administratively collected data in Turkey revealed that "In 2016, the Turkish government announced a work permit system to tackle the Syrian employment problem, but the program is not popular...only about 32,000 Syrians have received work permits to date. Syrians face a number of obstacles and disincentives when applying for work permits. First, to acquire a work permit, they must work in the province in which they are registered as under temporary protection. Since registration is required within 10 days of arrival in Turkey, however, this province is usually the one where the refugee entered Turkey. Therefore, refugees are disproportionately registered in the provinces bordering Syria, while the jobs tend to be elsewhere in big cities in western Turkey, such as Istanbul, Izmir, and Bursa. These destinations are naturally where many of the refugees go and work, regardless of registration, but they do so as part of the underground economy [14]." This administratively collected data is now useful in addressing this particular issue with resettlement and decrease the time to self-sufficiency with the individuals involved. This is just a single example of the importance of administrative procedure as a factor to successful resettlement.

\subsubsection{Health and Shelter}

During the resettlement phase, health care needs to be provided to the refugees. In doing so, this factor will affect the cost and the crime rate of the shelter. Although health care is a large expense, it will ensure a high survival rate. The more services physicians provide, the higher the cost will be to maintain that standard of care. As a result of having healthier patients both physically and mentally, the crime rate decreases. The opposite will occur if no health care is provided.

The health care set by the host government is completely structured by the federal policies of said government. The benefits that refugees receive are based on federal administrative regulations. Adversely, health care is dependent on federal policy, and not the other way around. In terms of economics, a government-subsidized health care program can create an entirely new market of jobs, specifically ones set up to support the refugees as they are taken in. Economics slowly transforms from micro to macro level depending on the length of government-funded care, and the number of refugees supported.

\subsubsection{Education and Training Programs}

Education and training programs are crucial for refugees to adapt and make a life for themselves in a society. Without these programs, refugees are left to fend for themselves and survive in a culture they are most likely very unfamiliar with. A major challenge for refugees, namely children, is that most education systems do not always accommodate foreigners the same way that they accommodate children that native citizens in that country. Even within the same host country individuals from different regions may have diverse educational needs [15]. This leads to further challenges as these children grow up and attempt to 
start a career because they are immediately at a disadvantage due to the lack of education forced upon them [15].

With proper education and training programs, however, refugees can start their new lives with newfound skills and knowledge, further improving their chance at thriving in a new country and increasing the rate of achieving self-sufficiency. Another added benefit to these programs is that with the added prestige of education and training, they will be better equipped to combat any possible discrimination they might endure as they will be equally educated as the native population.

One third of the 50,000 refugees that the United States has excepted per year for the last decade are children [16]. For these children the challenge of finding education may be difficult [17]. Fortunately, the National Education Association (NEA) provides a list of resources for those in search of education and support. The list provides several links for refugees to reference, in which provide information on where they may find education [18]. The most recent data shows that there are more than 840,000 immigrant students in the United States [10]. Existing programs such as the English Language Acquisition Program and the Migrant Immigration Programs offer federal and state funding to these children in need of assistance [19]. The UN Refugee Agency provides 18.5 million people assistance in 134 countries around the world, providing many of those such immigrants the opportunity for education [19]. Education can provide refugees the knowledge and skills to rebuild their lives and develop a path to a more peaceful and flourishing future for themselves and their families.

\subsubsection{Self Sufficiency}

In order to help refugees become self-sufficient, there must be help from the country where they are settling in. In the United States, the Refugee Career Pathways program helps refugees to achieve self-sufficiency by providing different types of training. The training consist of, assistance in creating personalized career development plans, classroom and work-based learning opportunities, career coaching and mentoring, connections with educational opportunities, apprenticeships, on-the-job training, re-credentialing and credential recognition, and vocational English language training [20]. In Germany, it is mandatory for refugees who lack German language competence to participate in integration courses. Refugees who sign up for vocational programs are more likely to be recruited by the German government to work [21]. In 2016, the German government and the German Confederation of Skilled Crafts planned to create a nationwide program in order to prepare refugees into their apprenticeship. With this program refugees will be trained in different trades such as metal and electrical work. They would also be able to take language and integration classes [22].

\subsubsection{Safety and Security}

"Protecting the physical security of refugees entails securing their areas of residence, or taking steps to prevent their safety from being jeopardized. It also requires that the living environment of refugees should be peaceful, humanitarian and civilian, free of violence and criminal activity, and conducive to the realization of human dignity... [23]". Crime rate is something we want to take precaution when it comes to refugees. There are plenty of federal policies that prevent crimes within refugee establishments. Upon researching crime rate in refugee camps with large number of refugees became noticeably more safe, both in terms of their levels of violent and property crime [24]. However, we should not rule out this possibility because there are petty crimes that do occur within the establishment. No doubt that some countries have federal policies to prevent crimes, but some countries don't have policies to enforce upon refugees.

\subsubsection{Social Issues and Economic Impact}

Economic issues that affect the countries where refugees reside are mainly in the cost of their well-being. The governments of those countries are responsible for food, housing, and education to name a few. Large scale refugee populations can have serious impact on the social, economic and political life of host countries (in particular developing countries) and creates strain on the local administration. Refugees will compete 
with the host country citizens for resources of host countries. Gradually, their presence will cause to considerable demands on natural resources, education and health facilities, energy, transportation, social services and finally employment [25].

The economic impact of refugees on host countries can also be positive-an economic stimulus may be generated by the refugees and can help to further development of the host regions. Communication issues will negatively impact the ability of the refugees to find employment, which will alienate them from being accepted and integrated into the host society. "In Turkey, where a huge population of refugees have unprecedented access to quality government services but only in a foreign language, language has become a pivotal issue. This goes both ways: Syrian refugees need to learn Turkish especially to access education and jobs and to participate in community life, and government officials need Arabic-Turkish interpreters in order to provide individual services including registration, legal aid, health services and MHPSS (Mental Health and Psycho-Social Services) [26]." The ability to create social relationships is compromised by the language barrier and further inhibits integration into the host society. "Only one in every four refugee women says they have Turkish friends. A total of 79.7 percent of women say it is because they 'don't speak Turkish' that they could not make friends, while 10.4 percent say their immediate circle of acquaintances are entirely Syrian and they can only communicate with people of their own ethnicity. Some 10.4 percent say Turkish and Syrian culture are not different." [27] The impact of the language barrier is especially hard on refugee children. "Language barriers can make refugees feel isolated, hopeless, and anti-social, which often leads to depression. Struggling with speaking and comprehension makes it difficult for refugees to make friends with...peers and can unfortunately make them a target for bullying. It also leads to a lack of confidence, inhibiting many from speaking up and participating in class, and ultimately missed job and educational opportunities [28].

The social issues that affect the refugee population can range from poverty, racism, social disorganization, public health, social inequality, and many more. Many social issues last for the rest of the refugee's lives. Economic and social issues are real part of the refugee crisis that should be addressed. The international community should help compensate for the costs required in providing reasonable lifestyle for the refugees [25].

\subsection{Interpretive Structural Modelling (ISM)}

\subsubsection{Structural Self-Interaction Matrix (SSIM)}

The above factors are assumed to be interrelated, rather than independent, where it is noted that some factors may increase the effects of other factors. The next step was to determine contextual relationship to develop structural self-interaction matrix shown in Figure 3. Using expert opinions along with working members the SSIM was developed. As shown in Figure 2, combination of these three steps is called Transdisciplinary Collective Intelligence Development [29].

Contextual relationship for each factor, the subsistence of a relation between any two factors ( $\mathrm{i}$ and $\mathrm{j}$ ) and the associated direction of the relation are questioned. The following four symbols are used to denote the direction of relationship between the factors (i and $\mathrm{j}$ ):

- V: Variable i affects variable $\mathrm{j}$

- A: Variable j affects variable i

- X: Both variables, i and $\mathrm{j}$, affect each other

- O: No relationship between variables $i$ and $j$

Considering on the contextual relationships, the structural self-interaction matrix (SSIM) shown in Figure 3 was developed for the nine main factors. 


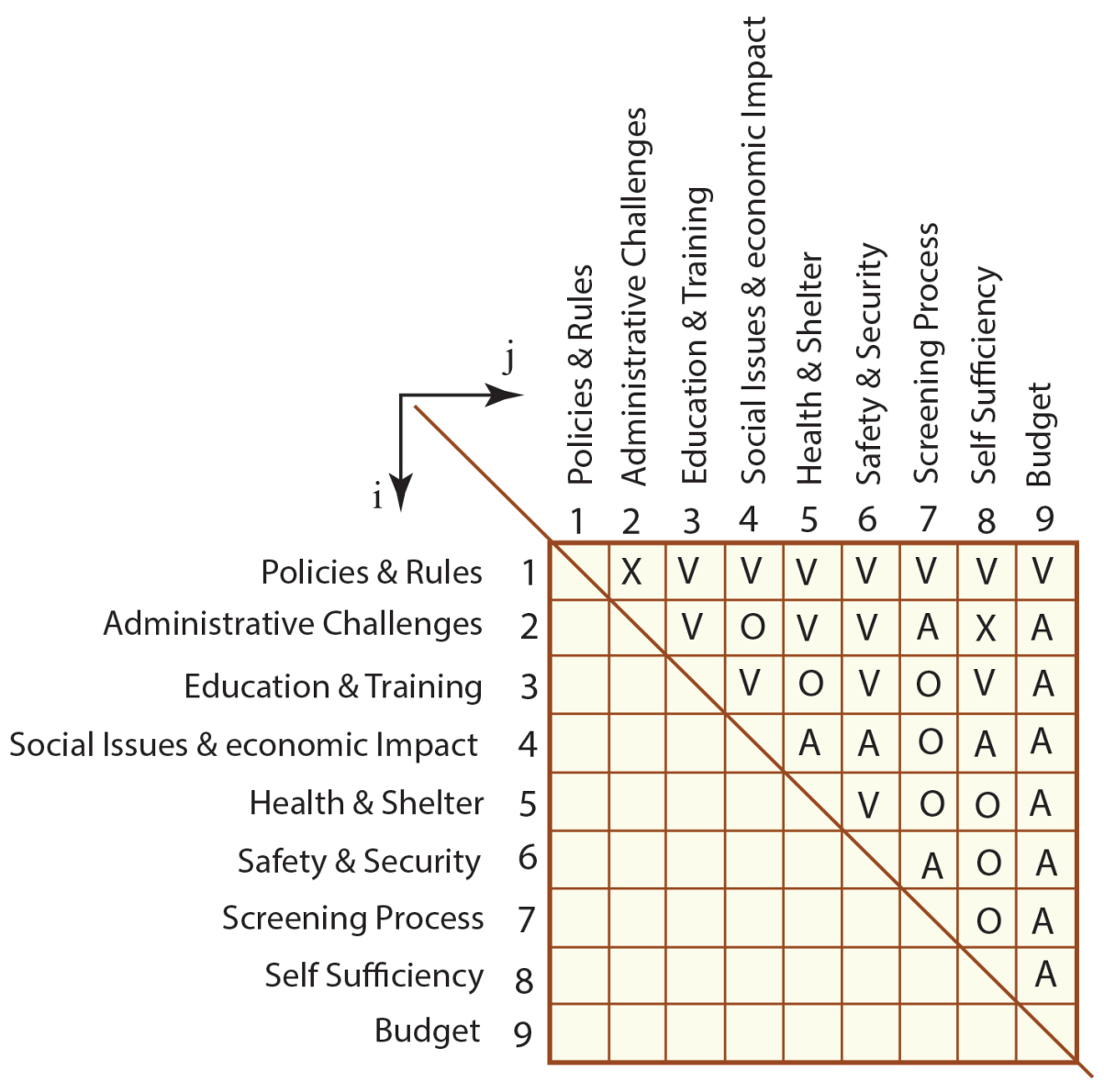

Figure 3: Structural Self-Interaction Matrix (SSIM).

\subsubsection{Adjacency matrix}

Then the adjacency matrix, $R_{a}$, shown in Figure 4 is developed via transforming SSIM into a binary matrix, by substituting $\mathrm{V}, \mathrm{A}, \mathrm{X}$, and $\mathrm{O}$ by 1 and 0 per the schema described below:

- Enter ' $V$ ' when the relation is from $i$ to $j$ (in the reachability matrix substitute in the $(i, j)$ entry as 1 and (j,i) entry as 0$)$.

- Enter ' $\mathrm{A}$ ' when the relation is from $\mathrm{j}$ to $\mathrm{i}$ (in the reachability matrix substitute in the $(\mathrm{i}, \mathrm{j}$ ) entry as 0 and ( $\mathrm{j}, \mathrm{i})$ entry as 1$)$.

- Enter ' $\mathrm{X}$ ' when the relation is from $\mathrm{I}$ to $\mathrm{j}$ and $\mathrm{j}$ to $\mathrm{I}$, both direction (in the reachability matrix substitute in the (i,j) entry as 1 and ( $\mathrm{j}, \mathrm{i})$ entry as 1$)$.

- Enter ' $\mathrm{O}$ ' when there is no relationship between the row (i) element and the column ( $\mathrm{j}$ ) element (in the reachability matrix substitute in the $(\mathrm{i}, \mathrm{j})$ entry as 0 and $(\mathrm{j}, \mathrm{i})$ entry as 0$)$.

\subsubsection{Reachability Matrix with Transitivity}

Using the transitivity rule, a reachability matrix, $R_{t}$, shown in Figure 5 was obtained. Transitivity rule states that, if a factor ' $\mathrm{A}$ ' is related to factor ' $\mathrm{B}$ ' and if factor ' $\mathrm{B}$ ' is related to factor ' $\mathrm{C}$ ', then factor ' $\mathrm{A}$ ' is related to factor ' $\mathrm{C}$ '. This matrix was updated until transitivity is established. 
Moran, D., Gulbulak, U. Ertas E., Students from 2020 Capstone Design, ME-Section-5 Class

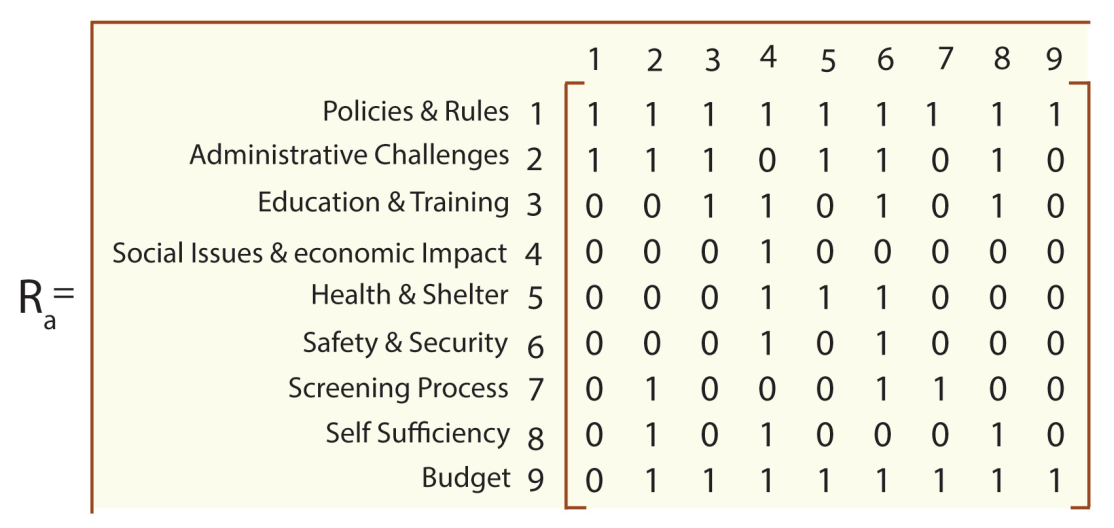

Figure 4: Adjacency matrix.

\begin{tabular}{|c|c|c|c|c|c|c|c|c|c|}
\hline & 1 & 2 & 3 & 4 & 5 & 6 & 7 & 8 & 9 \\
\hline Policies \& Rules 1 & 1 & 1 & 1 & 1 & 1 & 1 & 1 & 1 & 1 \\
\hline Administrative Challenges 2 & 1 & 1 & 1 & 1 & 1 & 1 & 1 & 1 & 1 \\
\hline Education \& Training 3 & 0 & 1 & 1 & 1 & 0 & 1 & 0 & 1 & 0 \\
\hline Social Issues \& economic Impact 4 & 0 & 0 & 0 & 1 & 0 & 0 & 0 & 0 & 0 \\
\hline Health \& Shelter 5 & 0 & 0 & 0 & 1 & 1 & 1 & 0 & 0 & 0 \\
\hline Safety \& Security 6 & 0 & 0 & 0 & 1 & 0 & 1 & 0 & 0 & 0 \\
\hline Screening Process 7 & 1 & 1 & 1 & 1 & 1 & 1 & 1 & 1 & 0 \\
\hline Self Sufficiency 8 & 1 & 1 & 1 & 1 & 1 & 1 & 0 & 1 & 0 \\
\hline Budget 9 & 1 & 1 & 1 & 1 & 1 & 1 & 1 & 1 & 1 \\
\hline
\end{tabular}

Figure 5: Reachability matrix for directed relationships between the elements with transitivity.

\subsubsection{Final Reachability Matrix}

The final reachability matrix as shown in Figure 6 was established by including driving power and dependence of factors. Summation of ones in the corresponding rows give the driving power and the summation of ones in the corresponding columns gives the dependence.

\subsubsection{Level Partition}

As shown in Table 1, The reachability and antecedent set for each variable are obtained from final reachability matrix [3]. Earlier obtained driving force and dependence from Figure 6 helps to classify the factors into groups. Positions of these group are determined by the separation of antecedent and reachability sets. From these two sets an intersection set is established. Next the factors which are common in the reachability set and antecedent set are included in the intersection set. These three sets help to identify the level of the factors. When all the factors of the intersection and reachability sets of any certain factor are the same, then that factor is identified as the top level of the ISM hierarchy. When the top level factors are known, it is discarded from the list of remaining factors to identify the next level. This iteration process is repeated until all the levels are identified. For example, the first iteration is given by Table 2. Since factor 4 has the same reachability set as the intersection set, factor 4 will be the top level of the ISM hierarchy. 


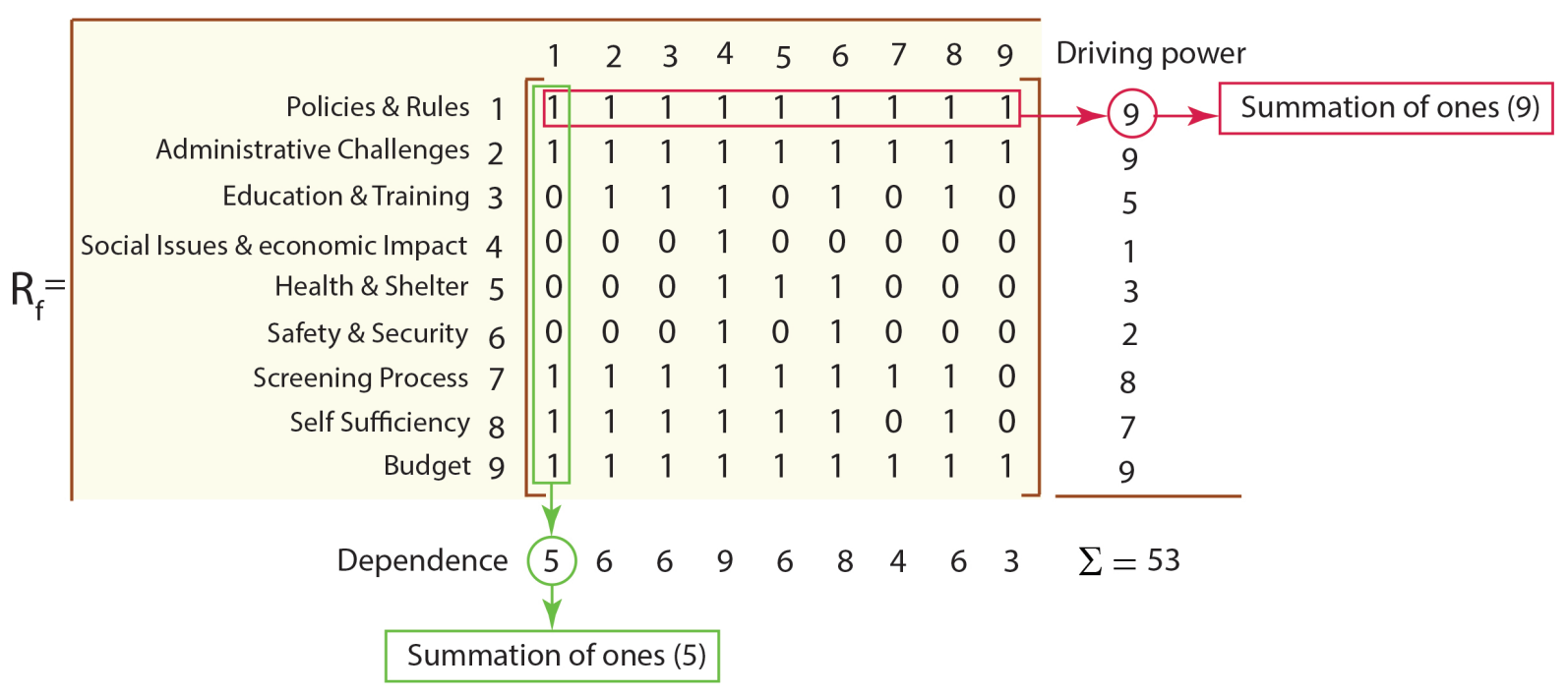

Figure 6: Final reachability matrix.

\subsubsection{Formation of Digraph}

The digraph is an illustration that shows the existence of the direct and indirect relationships between the factors. As shown in Fig. 7, the relationship of sets and binary associations through matrices can now be translated into graphical form by using theory of digraphs (directed graphs) [30]. If there is a relationship between factors and $\mathrm{j}$ has impact on $\mathrm{i}$, the connection between factors will go from $\mathrm{j}$ to $\mathrm{i}$.

\subsubsection{MICMAC Analysis - Classification of Performance Measures}

The MICMAC (Matrice d'Impacts Croisés Multiplication Appliquée á un Classement) (cross-impact matrix multiplication applied to classification) analysis is used to identify and to analyze the driving power and the dependence of the selected issues was developed by Duperrin and Godet in 1973 [31]. Through MICMAC analysis factors are arranged with respect to their driving power and dependence in four clusters [32]: (1) autonomous, (2) dependent, (3) linkage, and (4) independent factors. The driving power and dependence of each of factors are imported from Figure 6. Figure 8 shows the driving power-dependence map for refugee resettlement success factors.

\section{Discussions}

The factors affecting successful refugee settlement in a multi-project environment presented in Figure 7 show complex interactions among them. This complexity can be described using cyclomatic complexity through digraph as [33]:

$$
M=E-N+2 P
$$

where

$$
\begin{aligned}
& E=\text { the number of edges of the graph } \\
& N=\text { the number of nodes of the graph } \\
& P=\text { the number of connected components }
\end{aligned}
$$

The number of edges (depicted as arrows) shown in Figure 7 is 16, the number of nodes (depicted as rectangles) is 9 and the number of connected components, $P$ is equal to 1 . Then, the cyclomatic complexity $M$ of the digraph given in Figure is 
Moran, D., Gulbulak, U. Ertas E., Students from 2020 Capstone Design, ME-Section-5 Class

Complexity of Global Refugee Crisis: Needs for Global Transdisciplinary Collaboration

Table 1: Reachability set, antecedent set, iteration levels.

\begin{tabular}{|c|c|c|c|c|}
\hline Factor Numbers & Reachability Set & Antecedent Set & IntersectionSet & Factor Levels \\
\hline 1 & $1,2,3,4,5,6,7,8,9$ & $1,2,7,8,9$ & $1,2,7,8$ & \\
\hline 2 & $1,2,3,4,5,6,7,8,9$ & $1,2,3,7,8,9$ & $1,2,3,7,8,9$ & \\
\hline 3 & $2,3,4,6,8$ & $1,2,3,4,5,6,7,8,9$ & $2,3,8$ & \\
\hline 4 & 4 & $1,2,3,4,5,6,7,8,9$ & 4 & 1 \\
\hline 5 & $4,5,6$ & $1,2,5,7,8,9$ & 5 & \\
\hline 6 & 4,6 & $1,2,3,5,6,7,8,9$ & 6 & \\
\hline 7 & $1,2,3,4,5,6,7,8$ & $1,2,7,9$ & $1,2,7$ & \\
\hline 8 & $1,2,3,4,5,6,8$ & $1,2,3,7,8,9$ & $1,2,3,8$ & \\
\hline 9 & $1,2,3,4,5,6,7,8,9$ & $1,2,9$ & $1,2,9$ & \\
\hline 1 & $1,2,3,5,6,7,8,9$ & $1,2,7,8,9$ & $1,2,7,8,9$ & \\
\hline 2 & $1,2,3,5,6,7,8,9$ & $1,2,3,7,8,9$ & $1,2,3,7,8,9$ & \\
\hline 3 & $2,3,6,8$ & $1,2,3,7,8,9$ & $2,3,8$ & \\
\hline 5 & 5,6 & $1,2,5,7,8,9$ & 5 & \\
\hline 6 & 6 & $1,2,3,5,6,7,8,9$ & 6 & II \\
\hline 7 & $1,2,3,5,6,7,8$ & $1,2,7,9$ & $1,2,7$ & \\
\hline 8 & $1,2,3,5,6,8$ & $1,2,3,7,8,9$ & $1,2,3,8$ & \\
\hline 9 & $1,2,3,5,6,7,8,9$ & $1,2,9$ & $1,2,9$ & \\
\hline 1 & $1,2,3,5,7,8,9$ & $1,2,7,8,9$ & $1,2,7,8,9$ & \\
\hline 2 & $1,2,3,5,7,8,9$ & $1,2,3,7,8,9$ & $1,2,3,7,8,9$ & \\
\hline 3 & $2,3,8$ & $1,2,3,5,7,8,9$ & $2,3,8$ & III \\
\hline 5 & 5 & $1,2,5,7,8,9$ & 5 & III \\
\hline 7 & $1,2,3,5,7,8$ & $1,2,7,9$ & $1,2,7$ & \\
\hline 8 & $1,2,3,5,8$ & $1,2,3,7,8,9$ & $1,2,3,8$ & \\
\hline 9 & $1,2,3,5,7,8,9$ & $1,2,9$ & $1,2,9$ & \\
\hline 1 & $1,2,7,8,9$ & $1,2,7,8,9$ & $1,2,7,8,9$ & IV \\
\hline 2 & $1,2,7,8,9$ & $1,2,7,8,9$ & $1,2,7,8,9$ & IV \\
\hline 7 & $1,2,7,8$ & $1,2,7,9$ & $1,2,7$ & \\
\hline 8 & $1,2,8$ & $1,2,7,8,9$ & $1,2,8$ & IV \\
\hline 9 & $1,2,7,8,9$ & $1,2,9$ & $1,2,9$ & \\
\hline 7 & 7 & 7,9 & 7 & V \\
\hline 9 & 7,9 & 9 & 9 & \\
\hline 9 & 9 & 9 & 9 & VI \\
\hline
\end{tabular}

$M=16-9+2 \times 1=9$ 


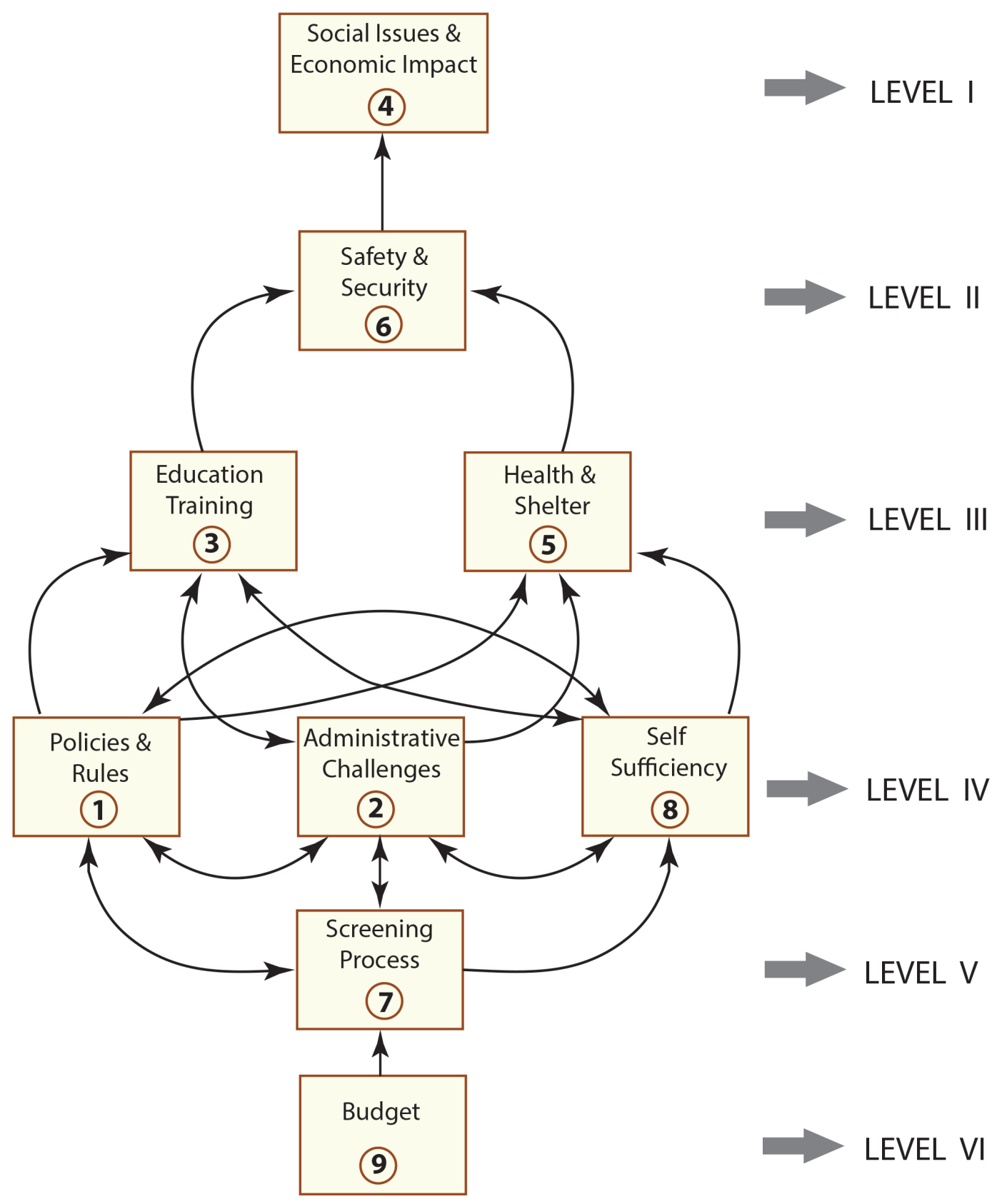

Figure 7: Digraph.

A higher number of cyclomatic complexity means that the complexity of an issue will be complicated to understand. The acceptable upper bound that has been used for cyclomatic complexity is 10 [33]. Since digraph gives close to a complexity of 10 , the issue of refugee settlement is too complex to understand. As seen from Figure 7, issue of refugee settlement consist of multiple levels of combinations and functional behaviors can arise at many of the levels. It is usually difficult in dealing with complex issues such as this one. The complexity of the refugee issue is due to the presence of many factors and interactions among these factors. The existence of directly or indirectly related factors complicates the solution of the issue 


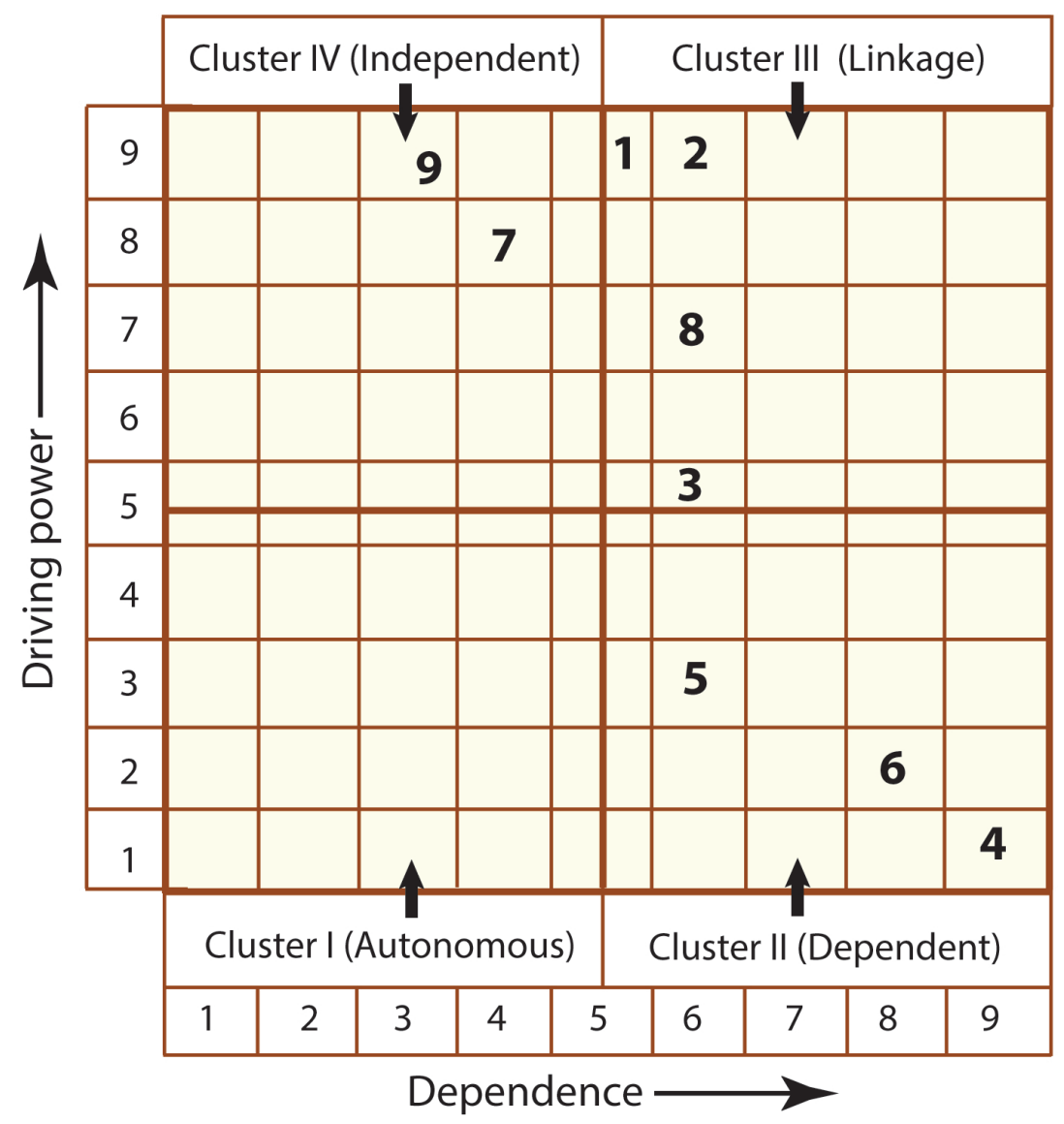

Figure 8: MICMAC Analysis.

which may or may not be articulated in a clear fashion.

The issue of refugee is complex and includes many factors. As shown in Figure 7, Level IV is the most complex one because of many interactions with the other levels. Administration plays important role for the success of the refugee settlement to implement policies and rules in order to help refugees become self-sufficient. Level IV effort should support education and training programs as well as health care needs which are crucial for refugees to adapt and make a life for themselves in a society. A source factor of establishing a realistic budget should be allocated to separated families, detained children, threatened immigrants and also all the required activities of secure and successful resettlement of refugees. However, this effort should not be at the cost of crucial education, housing, and nutritional assistance programs that promote public safety and improve poverty at hosting countries.

Figure 8 shows that there are no autonomous factors. The absence of these factors shows that all the considered factors influence the successful refugee resettlement. Hence, the management should pay attention to all the factors for a successful adoption of resettlement success measures. Health \& shelter, safety and security, and social issues and economic impact are in the category of dependent quadrant. This means that this issue has little driving power but strong dependence (called driven factors).

The linkage cluster consists of four factors, including that the policies and rules (factor 1), administrative challenges (factor 2), Self-sufficiency (factor 8), and education and training (factor 3). These factors have strong driving power, as well as strong dependence power, therefore, they are considered as key factors for the success of the refugee settlement. These factors are critical, meaning that any action on these factors may influence the other factors and an effect on themselves by the other factors. 
The fourth quadrant includes independent barriers that have a low dependence but strong driving power. In this research, budget \& cost (factor 9) and screening process (factor 7 ) are in this quadrant. It can be assumed that these factors may be considered as the important key parameters, as well as the root cause of problematic issues. Management should give the greatest attention to these factors in order to meet the terms of the success of the goal of the refugee settlement.

As shown in Figure 7, factors safety and security (factor 6), social issues and economic impact (factor 4) are positioned at the top of the hierarchy. They are also very significant measures for the successful development of a refugee settlement as they are being affected by the other factors: living environment of refugees should be peaceful, humanitarian and civilian, free of violence and criminal activity, and conducive to the realization of human dignity.

\section{Concluding Remarks}

It has been shown that the issue of refugee settlement consist of multiple levels of combinations and functional behaviors can arise at many of the levels - the problem of refugee settlement is too complex to understand. In this research, budget \& cost (factor 9) and screening process (factor 7) are considered as the important key parameters, as well as the root cause of problematic issues. Management should give the greatest attention to these factors in order to meet the terms of the success of the goal of the refugee settlement.

It is important to note that ISM is a tool to identify the order and directions of the complexity of relationships among the factors affecting certain issues. It does not provide any relative weight associated with the factors. Complex systems such as this one, require communications and exchange of information among responsible organizations. Information flow between organizations can be created using a Design Structure Matrix (DSM) in order to better map organizational responsibilities and their interactions to address the problems associated with the refugee resettlement. Clustering (integration) of organizations can provide new understandings into organizational decomposition and integration.

Contributions: D. Moran worked on the transdisciplinary collective intelligence development - obtained required information from domain experts. Also worked on the editing part of the manuscript. U. Gulbulak was the facilitator of the ICIM workshop. A. Ertas was the instructor of the class and supervised the project. The senior design class students participated in the ICIM workshop and also contributed to the final manuscript.

Funding: This research received no external funding.

Conflicts of Interest: The authors declares no conflict of interest.

\section{References}

[1] Global Trends forced Displacement in 2018, UNHCR, 2018. https://www.unhcr.org/5d08d7ee7.pdf, (accessed March 3, 2020).

[2] Halpern, P., (2008). Refugee economic self-sufficiency: an exploratory study of approaches used in office of refugee resettlement programs. https://aspe.hhs.gov/system/files/pdf/75561/report.pdf (accessed March 1, 2020).

[3] J. N. Warfield, (1974). Developing Interconnected Matrices in Structural Modeling. IEEE Transactions on Systems, Man and Cybernetic, 4(1), pp 51-58.

[4] Ertas A. (2016). Transdisciplinary Trans-Sector Integration in Education: Convergence. Transdisciplinary Journal of Engineering 63 Science, Vol. 7, pp. 55-68.

[5] Delbecq, A. L.; VandeVen, A. H (1971). A Group Process Model for Problem Identification and Program Planning. Journal of Applied Behavioral Science. 7, pp. 466-91. doi:10.1177/002188637100700404

[6] The Role of Federal Policy. Lumina Foundation. www.luminafoundation.org/federal-policy. 
Moran, D., Gulbulak, U. Ertas E., Students from 2020 Capstone Design, ME-Section-5 Class

[7] Villemez, J. (2011). 9/11 To Now: Ways We Have Changed. PBS, Public Broadcasting Service, 14 Sept. 2011 , www.pbs.org/newshour/world/911-to-now-ways-we-have-changed.

[8] Kanno-youngs, Z. (2020). Trump Administration Adds Six Countries to Travel Ban. The New York Times, The New York Times, 31 Jan. 2020, www.nytimes.com/2020/01/31/us/politics/trump-travel-ban.html (accessed February 18, 2020)

[9] An Overview of U.S. Refugee Law and Policy. American Immigration Council, 8 Jan. 2020, www.americanimmigrationcouncil.org/research/overview-us-refugee-law-and-policy. (accessed February 24, 2020).

[10] Government of Canada. Canada.ca, Government of Canada, 12 June 2017, www.canada.ca/en/immigrationrefugees-citizenship/services/refugees/welcome-syrian-refugees/security-health-screening.html.

[11] Kietz, D. (2015). Craving for Control: Refugee Screening in the EU and the US. Reshaping Europe, 15 Dec. 2015, reshaping-europe.boellblog.org/2015/12/15/craving-for-control-refugee-screening-in-theeu-and-the-us/.

[12] 2020 Planning Summary: Operation: Turkey. (2019, December 20). UNHCR. http://reporting.unhcr.org /sites/default/- les/pdfsummaries/GA2020-Turkey-eng.pdf

[13] Why is Turkey Pushing Refugees to Return to Syria? (2019, October 9). Tufts Now. https://now.tufts.edu/articles/why-turkey-pushing-refugees-return-syria

[14] Center for American Progress. (2019). Center for American Progress; Center for American Progress.

[15] L, Cerna. (2019). Refugee Education: Integration Models and Practices in OCED Countries. http://www. oecd.org/o ${ }^{-}$cialdocuments/publicdisplaydocumentpdf/? cote=EDU/WKP(2019)11\&docLanguage $=$En

[16] For Refugees in America, an Unful-lled Dream. Harvard Graduate School of Education, www.gse.harvard.edu/news/uk/18/02/refugees-us-unful ${ }^{-}$lled-dream.

[17] Resources for Supporting and Educating Migrant Refugee Children. NEA, www.nea.org/home/61723.htm.

[18] Educational Services for Immigrant Children and Those Recently Arrived to the United States. Home, US Department of Education (ED), 19 Sept. 2014, www2.ed.gov/policy/rights/guid/unaccompanied-children.html.

[19] Providing Worldwide Refugee Aid. UNHCR Canada, www.unhcr.ca/where-we-work/world/.

[20] Refugee Career Pathways. ACF, www.acf.hhs.gov/orr/programs/refugee-career-pathways.(accessed February $26,2020)$

[21] The State of Refugee Integration in Germany in 2019. WENR, 8 Oct. 2019, wenr.wes.org/2019/08/the-stateof-refugee-integration-in-germany-in-2019. (accessed February 26, 2020)

[22] Davis, A. (2017). Refugee Apprentice: Germany $\mathrm{O}^{-}$ers Skills Training to Newcomers. Refugees, News Deeply, 24 Feb. www.newsdeeply.com/refugees/articles/2017/02/22/refugee-apprentice-germany-o ${ }^{-}$ers-skills- $^{-}$ training-to-newcomers, (accessed February 26, 2020).

[23] Protection Guidelines Relating to Refugee Security. https://www.refworld.org/pdfid/4124bee54.pdf. Accessed March 13, 2020.

[24] Is There a Link Between Refugees and U.S. Crime Rates? (2017). American Economy. https://research. newamericaneconomy.org/report/is-there-a-link-between-refugees-and-u-s-crime-rates/, accessed February 25, 2020.

[25] Social and economic impact of large refugee populations on host developing countries, EC/47/SC/CRP.7, UNHCR Standing Committee (1997). https://www.unhcr.org/en-us/excom/standcom/3ae68d0e10/socialeconomic-impact-large-refugee-populations-host-developing-countries.html. Accessed March 12, 2020.

[26] Evaluation of UNHCR's Emergency Response to the inux of Syrian Refugees into Turkey Evaluation Service. (2016). https://www.unhcr.org/58a6bbca7.pdf

[27] Language remains main barrier for Syrian female refugees. (2018, May 1). DailySabah. https://www.dailysabah.com/turkey/2018/05/01/language-remains-main-barrier-for-syrian-female-refugees

[28] LANGUAGE Integration Barriers: Perspectives from Refugee Youth. (n.d.). BRYCS. https://brycs.org/migration-resettlement-awareness/language-integration-barriers-perspectives-from-refugeeyouth/ 
[29] Aldana M. et al., (2019). Just-in-Time Supply Chain Innovation through Additive Manufacturing: A Transdisciplinary Educational Experience. Transdisciplinary Journal of Engineering 65 Science, ISSN: Vol. 10, pp. 199-223.

[30] F. Harary, R. V. Norman and D. Cartwright, Structural Models: An Introduction to the Theory of Directed Graphs, Willey, New York, 1965.

[31] J. C. Duperrin and M. Godet, Methode De Hierar Chization des Elements D'um System, Rapport Economique de CEA, 1973, pp.45-51.

[32] A. Mandal and S. G. Deshmukh, Vendor Selection Using Interpretive Structural Modelling (ISM), International Journal of Operations \& Production Management, 14(6), 1994, pp. 52-59.

[33] McCabe, T. J., "Describing Cyclomatic Complexity," IEEE Transactions on Software Engineering, Vol. 2, No. 4, p. 308, 1976.

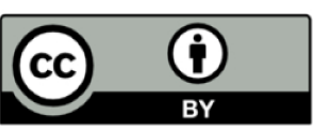

Copyright (C)2019 by the authors. This is an open access article distributed under the Creative Commons Attribution License (https://creativecommons.org/licenses/by/4.0/), which permits unrestricted use, distribution, and reproduction in any medium, provided the original work is properly cited. 